\title{
System analysis of remote sensing data on structural control of diamondiferous areas
}

\author{
Sokolovsky A.K, Serokurov Yu.N., Kalmykov V.D.
}

To date main natural diamond receptacles are kimberlites and lamproites found practically in all the continents of the world. Natural groupings of these rocks in outer crust form mineragenetic taxons, each having its own structural control forms.

Numerous concepts concerning structural control of diamondiferous magmatites can be reduced to the following postulates. Diamondiferous areas: are confined to platform blocks of the Earth's crust with Pre-Cambrian basements and (more rarely) to their folded frames; are generally governed by regional linear structures of mantle origin and repeated activation; are concentrated at points of intersection between the above structures and similar ones; are marked by ring structures of crystalline basement resulted from formation and evolution of deep-seated hearths of central type.

An investigation of the position of diamondiferous areas based on remote sensing data demonstrated that there is a considerable reserve in deciphering new forms of their structural control. Satellite images are effective in distinguishing block and fault structures of various depth and origin. They are detected by linear, concentric or concentric and radial arrangements of orohydrographic, soil, vegetative and other landscape elements as well as textures, tones and colours of images resulted from composition of geologic substratum.

Considerable scale range of satellite survey of the planet surface provides for distinguishing wide spectrum of variously ranked structures located at different depths including those controlling diamond taxons. Specific character of the material used allows to systematise separate data and select those related in a varying degree to diamondiferous objects.

Planet control systems of diamondiferous areas. Examination and processing of small resolution satellite images of some continents ( the north of Europe and Asia, Africa, South America, Australia, India and a part of Antarctica) allowed to detect within their boundaries the traces of huge (up to 10 thousand $\mathrm{km}$ in diameter) concentric and radial systems by lineament concentrations of the global scale. In the southern hemisphere the integrated picture of these systems was obtained only by reconstructing the positions the continents had before their separation in Mesozoic. Studies of satellite gravimetry data on the above territories confirmed the existence of concentric-radial structures. 
It is important to note that concentric-radial systems on different continents have similar organization and apparent long development history. One may assume that they served as carcass in forming the Earth's crust architecture during first of all Pre-Mesozoic history of the Earth.

Central parts of concentric-radial systems (within the contours of ancient platforms) can be treated as the most prospective structures favorable for formation of diamondiferous provinces. General analysis of dislocations of the areas exhibiting kimberlite magmatism in respect to the elements of East Siberian, East European, South American-African and Australian systems showed that 90 per cents of such areas are controlled by their concentric-radial components. That is, these are areas inside the platforms that are most prospective for searching for kimberlite-enclosed zones.

Continental structures that control diamond potential. More detailed studies of small resolution satellite images supported by those of medium resolution revealed ovoidal-radial structures one-two thousand $\mathrm{km}$ in diameter within ancient platforms. Arc and radial elements that constitute the structures are considered as zones of high tectonic activity and permeability in the course of the whole history of lithosphere development, which predetermines the fact that early PreCambrian sutural depressions (throughs), fragments of rift systems and sections of differently aged magmatism are all confined to them. These formations are apparently younger than concentric- radial zones since their core parts occupy a rather definite position in the nodes of intersections between arc and radial elements of the latter ones and, on the whole, they form a peculiar cell structures of the second-cycle platform.

Projection of such structures on platform surfaces may be considered as an indicator for possible formation of diamondiferous "subprovince"-ranked taxons that govern the arrangement of higher-ranked taxons.

Local structures that control diamond potential. The analysis of medium resolution satellite images on a number of known diamondiferous areas (Malo-Botuobinskaya, DaldynoAlakitskaya, Arkhangelskaya in Russia, Orapa, Dzhvaneng, Pretoria, Kimberly in South Africa, West and East Kimberly in North-East Australia) performed by us showed within their boundaries universal presence of complex ring structures that outline the areas of kimberlite and cognate rock development. Similar size and morphology of structural forms that are determined on several areas with different geological composition and landscapes allow to treat them as obligatory characteristics of a "region"-ranked taxon that generally comprise several fields within a contour.

For the most part the fields of kimberlites and their related rocks occur within the core and in the central zone of the structures.. They have spatial trend towards the largest radial and arc elements of these structures as well as the nodes of their intersections. The fields are mostly concentrated within the zones related to ovoidal and radial structures of the preceding rank that tend to form an intersection node between themselves within the regions. 
Detailed structures that control diamond potential. Concentrations of kimberlite bodies within the region at first sight are arranged in a rather random manner. However, on closer inspection kimberlites and lamproites are noted to have strict spatial trend to the most disturbed sections, namely the sections of cone boundaries of cores and middle zones, radial zones influenced by lower- scaled tectonic elements.

In the sections of the greatest concentration of kimberlite clusters the analysis of satellite images of detailed resolution reveals ring structures $30-50 \mathrm{~km}$ in diameter resulted either from energy impulses encouraging rapid kimberlite magma transportation from the mantle to the surface or from intracrust magmatic hearths where mantle magmatite evolution and kimberlite magma separation took place during definite activation periods.

Last to be considered in diamondiferous sequence are kimberlite and lamproite bodies that often have a pipe form, although dikes and sills are also globally occur. Within open territories they are represented on the surface by positive and negative forms of modern landscape.. When pipes are overlain by more recent formations their recognition on the images is difficult.

Summing up the aforesaid one may conclude that practically the whole taxonometric sequence of diamondiferous areas is controlled by the structures originated due to abyssal processes and definite organization of mantle and crust composition. These structures are responsible either for regional position of diamondiferous taxons or for the characteristics of their internal composition. Revealing the structures of the corresponding types is a methodical task of a particular scale of the investigation and the need to select successively first regional and then local diamond-controlling structures is dictated by the methods of system analysis that allows to achieve the end result with minimum time and cash expenditures.

\section{References.}

Brukhanov V.N., Bush V.A.,Glukhovsky M.Z. and others. Ring structures of the Earth's continents. M., Nedra, 1987.

Glukhovsky M.Z., Kats Y.G. Ring structures of the Earth. M., Nedra, 1983.

Moralyov M.M.,Glukhovsky M.Z. Precambrian shield ring structures based on satellite images interpretation data. Space investigations of the Earth, 1981, ${ }^{13}$.

Serokurov Yu.N., Kalmykov V.D. Ring structures of the Earth and diamond potential.Otechestvennaya geologia, ${ }^{1} 11,1996$.

Feldman \& Olofinsky. Structural and geoghysical environments of kimberlite fields on ancient platforms. Geology and prospecting.N 9,1991.

Shkodzinsky V.S. Magmatic rock origin and prospects for diamond potential of a region based on magmatic criteria, In: Geology and diamond potential of the south-eastern margin of the Siberian platform and Sette-Dabana. M.,Nedra, 1996. 